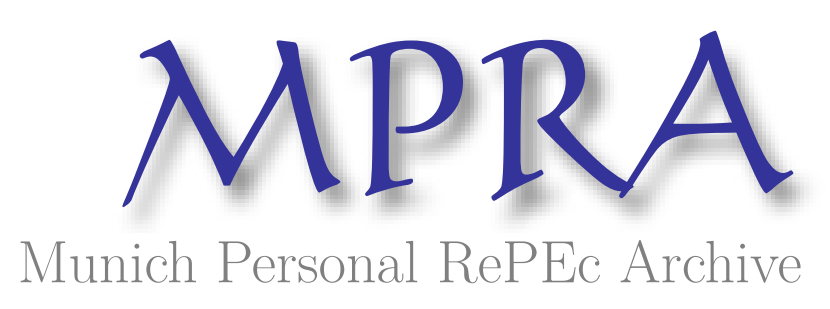

\title{
Properties of an economy without human beings
}

Kakarot-Handtke, Egmont

13 June 2011

Online at https://mpra.ub.uni-muenchen.de/32535/

MPRA Paper No. 32535, posted 02 Aug 2011 01:33 UTC 


\title{
Properties of an Economy Without Human Beings
}

\author{
Egmont Kakarot-Handtke
}

\begin{abstract}
Standard economics starts with behavioral axioms and arrives at conclusions about the equilibrium properties of the economy as a whole at point $t$. The present paper employs objective structural axioms and random changes in order to determine the conditions for market clearing and budget balancing in the pure consumption economy until the limit $t \rightarrow \infty$. From the conditions of stochastic supersymmetry six simple behavioral rules are derived that guarantee the desired outcome. These rules contrast with actual behavior and this explains why the plans and expectations of economic man are many times frustrated.
\end{abstract}

JEL D50, E20, E30, E40

Keywords New framework of concepts, Structure-centric, Axiom set, Random consumption economy, Evolutionary properties, Benchmark process, Stochastic supersymmetry, Structural laissez-faire 


\section{Parochial realism and the reduction of complexity}

Theory has aptly been compared to a map that reduces the overwhelming complexity of the real thing to manageable proportions. As a first step to a useful map parochial realism translates the real thing into commonplace economics (Niehans, 1994, p. 15) which maintains:

- Successive units of a commodity are less and less urgently needed.

- Abundance makes prices fall a scarcity makes them rise.

- A decline in price stimulates demand but reduces supply.

- Higher fertility and better location result in higher land rent.

- An increase in the money supply raises prices.

- Voluntary exchange is advantageous to both parties.

- Trade occurs because different regions have different natural endowments.

The salient trait of this pre-theoretical raw material is that it articulates myopic impressions of a fairly developed economy with prices, rent, and money that is historically located somewhere between a barter economy and the globalized economy.

For the history of economic science, the concept of commonplace economics is useful mainly as a benchmark from which analytical achievement can be measured. It marks the zero point of scientific progress. (Niehans, 1994, p. 15)

What is needed first to make scientific progress is a corresponding analytical zero point. The crucial requirement thereby is that the analytical starting point must embrace the whole economy - in contradistinction to parochial realism. To insist on this requirement is the distinguishing merit of general equilibrium theory in comparison to the Marshallian approach that has to protect its open flanks with ceteris paribus. This analytical expedient is unwarranted because circular interdependencies are the defining characteristic of the economy. Therefore, as a matter of principle, no partial approach of any kind will do. Methodologically partial analysis has the additional drawback that it almost certainly leads to the fallacy of composition.

The task is to create a map of the whole economy without firsthand experience because THE ECONOMY is invisible and intangible. That is, one has to leap from commonplace economics to an extremely abstract set of basic propositions about the economy as a whole. This set has to reduce the vast complexity of the real thing to almost nothing. From this almost-nothingness the real world complexity then has to be logically reconstructed. This is done by the cumulative introduction of more specific assumptions, real world restrictions, and historical contingencies. 


\subsection{The place of human beings in economic theory}

J. S. Mill gave human beings the central position in his theoretical universe by introducing the behavioral principle:

Just in the same manner [as geometry] does Political Economy presuppose an arbitrary definition of man, as a being who invariably does that by which he may obtain the greatest amount of necessaries, conveniences, and luxuries, with the smallest quantity of labour and physical self-denial with which they can be obtained in the existing state of knowledge. (Mill, 2004, p. 110)

In fact, with his definition of economic man Mill did two things at once. He in addition installed a tight coupling between his behavioral hypothesis and the axiomatic method as the reference to geometry testifies (see also Mill, 2006, p. 746). Thereby he left parochial realism behind.

Their [the classical economists'] achievements therefore were analytical and it is this which is usually meant by the most unfortunate terms 'deductive', 'abstract', 'aprioristic'. Their chief aim was to order intellectually and to clarify the day to day happenings in the economy in order to arrive at an axiomatic understanding of its basic factors. (Schumpeter, 1954, p. 90)

Since in Mill's days Euclidean geometry was, for all practical purposes, identical with mathematics, the mathematization of economics, in a broad sense, started with the classics. The conspicuous preoccupation with the calculus came with the neoclassicals' establishment of the marginal principle as a passepartout for explaining economic behavior. Mill's coupling had at first no effect with regard to rigorous formalization, because the classical economists relied mainly on verbal reasoning and numerical examples to expound their theories. Nevertheless, they firmly established the axiomatic method in economics (Stigum, 1991, p. 4).

Cournot was the first who, without challenging the realism of Mill's behavioral principle, objected against assigning it the role of the methodological cornerstone analogous to the axioms in Euclidean geometry:

The abstract idea of wealth or value in exchange ... must be carefully distinguished from accessory ideas of utility, scarcity and suitability to the needs and enjoyment of mankind .... These ideas are variable, and by nature indeterminate and consequently ill suited for the foundation of a scientific theory .... (Cournot 1897, quoted in Mirowski, 1995, p. 208), see also (Ingrao and Israel, 1990, pp. 38, 41, 47, 81)

Cournot clearly realized that behavioral assumptions are too weak to carry an extended theoretical superstructure. Cairnes, on the other hand, accepted human behavior as cornerstone of the theoretical edifice but did not discriminate between branches of mathematics, the axiomatic method, and quantification and rejected all in one as inapplicable to economics: 
What I venture to deny is the doctrine which Professor Jevons and others have advanced - that economic knowledge can be extended by such means; that Mathematics can be applied to the development of economic truth, as it has been applied to to the development of mechanical and physical truth; and, unless it can be shown, either that mental feelings admit of being expressed in precise quantitative forms, or, on the other hand, that economic phenomena do not depend upon mental feelings, I am unable to see how this conclusion can be avoided. (Cairnes, 1875, p. iv-v)

Methodologists of our days have arrived at the bottom line that to base economic theory on assumptions about human behavior is not a progressive research program:

The failure of microeconomic theory to uncover laws of human behavior is due to its wrongly assuming that these laws will trade in desires, beliefs or their cognates. And the system of propositions about markets and economies that economist have constructed on the basis of its assumptions about human behavior is deprived of improving explanatory and predictive power because its assumptions cannot be improved in a way that transmits improved precision to their consequences. (Rosenberg, 1994, p. 224)

Two conclusions may be drawn from this scant overview. First, the axiomatic method is inapplicable to economics, or, second, it is inapplicable to human behavior. If economics is identified with utility and profit maximization both conclusions amount to the same.

The present paper is about the switch of the unifying principle from the behavioral axioms represented by homo economicus to structural axioms. Human beings are thereby moved to the analytical background. This amounts to a decoupling of behavioral assumptions and the axiomatic method. Behavioral assumptions are denied the formal status of axioms. Hence the main thesis says that human behavior does not yield to the axiomatic method, yet the axiomatization of the money economy's fundamental structure is feasible.

By choosing objective structural relationships as axioms behavioral hypotheses are not ruled out. On the contrary, the structural axiom set is open to any behavioral assumption and not restricted to the standard optimization calculus.

\subsection{The natural way to proceed}

Hilbert described the axiomatic approach as a fairly general method of research:

When we assemble the facts of a definite, more-or-less comprehensive field of knowledge, we soon notice that these facts are capable of being ordered. This ordering always comes about with the help of a certain framework of concepts [Fachwerk von Begriffen] .... The framework of concepts is nothing other than the theory of the field of knowledge. 
... If we consider a particular theory more closely, we always see that a few distinguished propositions of the field of knowledge underlie the construction of the framework of concepts, and these propositions then suffice by themselves for the construction, in accordance with logical principles, of the entire framework. (Hilbert, 2005, p. 1107), original italics

It deserves emphasis that Hilbert's characterization refers to a consistent framework of concepts and does not mention formalization at all. The fuss about the use and abuse of mathematics in economics is thereby deflated to the real proportions. Formalization has its own merits (Suppes, 1968, pp. 654-655) and is not the same as axiomatization (Boylan and O'Gorman, 2007, pp. 430, 432). Coherent concepts come first. It is striking that virtually all fundamental economic concepts like income, profit, capital, equilibrium or the long run are ill defined and idiosyncratic to each school of thought. Conceptual fuzziness and 'loose verbal reasoning' (Dennis, 1982, p. 698) are the home-grown causers of effectless disagreement among economists (cf. Prychitko, 1998).

Henri Poincaré gave a felicitous characterization of the axiomatic enterprise:

The essential thing is to learn to reason with the axioms once admitted. Uncle Sarcey, who loved to repeat himself, often said that the audience at a theatre willingly accepts all the postulates imposed at the start, but that once the curtain has gone up it becomes inexorable on the score of logic. Well, it is just the same in mathematics. (Poincaré, 2007, p. 136)

As it happens, it is just the same in economics - with one crucial difference. In pure mathematics axioms are, as a matter of principle, empirically vacuous; in theoretical economics, to the contrary, they must not, because economics is located 'somewhere on the intersection between pure and applied axiomatic systems' (Rosenberg, 1994, p. 230).

Accordingly we now proceed as follows. The formal starting point is set with the structural axioms in section 2 and then consistently extended until section 6 . Human beings and the production process are replaced by a random number generator. In section 7 the formal conditions for the supersymmetric market outcome of the random consumption economy are derived. An economic interpretation of the long run limit state is given in sections 8 and 9. From the analysis follow six elementary rules of behavior in the consumption economy that are conductive to short run supersymmetry in the product market and full employment. Section 10 concludes.

\section{Curtain up}

The first three structural axioms relate to income, production, and expenditures in a period of arbitrary length. For the remainder of this inquiry the period length is conveniently assumed to be the calendar year. Simplicity demands that we have for 
the time being one world economy, one firm, and one product (the differentiation is carried out in Kakarot-Handtke, 2011c).

Total income of the household sector $Y$ in period $t$ is the sum of wage income, i.e. the product of wage rate $W$ and working hours $L$, and distributed profit, i.e. the product of dividend $D$ and the number of shares $N$.

$$
Y=W L+D N \quad \mid t
$$

Output of the business sector $O$ is the product of productivity $R$ and working hours.

$$
O=R L \quad \mid t
$$

Consumption expenditures $C$ of the household sector is the product of price $P$ and quantity bought $X$.

$$
C=P X \quad \mid t
$$

The first three axioms represent the pure consumption economy, that is, no investment expenditures, no foreign trade, and no taxes or any other state activity.

The period values of the variables are connected formally by the familiar growth equation, which is added to the structural set as the fourth axiom:

$$
Z_{t}=Z_{t-1}\left(1+\dddot{Z}_{t}\right)
$$

The path of the representative variable $Z_{t}$, which stands for the seven elementary $(W, L, D, N, R, P, X)$ and the three composed $(Y, O, C)$ axiomatic variables is then determined by the initial value $Z_{0}$ and the rates of change $\bar{Z}_{t}$ for each period:

$$
Z_{t}=Z_{0}\left(1+\dddot{Z}_{1}\right)\left(1+\dddot{Z}_{2}\right) \ldots\left(1+\dddot{Z}_{t}\right)=Z_{0} \prod_{t=1}^{t}\left(1+\dddot{Z}_{t}\right)
$$

Henceforth we use an abbreviated notation for the path operator:

$$
Z_{t}=Z_{0} \Pi \dddot{Z}_{t}
$$

Thus the price in period $t$, for example, is formally derived from the known price in period $t-1$ and the actual price change in period $t$, which depends on the decision makers' goals, on their subjective interpretations of the actual situation and on their expectations about the future. Because of the irreducible complexity of human beings we know next to nothing about these volatile factors.

\section{Change and Chance}

Equation (5) describes the paths of the axiomatic variables with the rates of change as unknowns. These unknowns are in need of determination and explanation. Since 
we refrain from speculations about human behavior, we have to choose the random hypothesis, because:

The simplest hypothesis is that variation is random until the contrary is shown, the onus of the proof resting on the advocate of the more complicated hypothesis ... (Kreuzenkamp and McAleer, 1995, p. 12)

Equation (5) then in effect says that human decision makers and the production process are black boxes that deliver a random rate of change in each period. Change comes in three versions: change of place, change of quantity and change of quality (Georgescu-Roegen, 1971, p. 61). In the following we are concerned solely with quantitative change. This, admittedly, is a narrow view. A comprehensive account of the diverse aspects of evolutionary change has been given by Nelson (1995). A theory of economic change was what Marshall, Jevons, and Walras expected to be developed by their successors (Keen, 2004, p. 218), (Foster, 2005, p. 377).

The theory of stochastic economic processes and in particular the notion of a fair game dates back to Bachelier (Davis and Etheridge, 2006, pp. 11-14). After a considerable time lag the concept had been taken up by Samuelson and was developed further by others (LeRoy, 1989, p. 1588), (Mirowski, 2004, pp. 255259).

To begin with it is assumed that changes in the axiomatic random economy ${ }^{1}$ are symmetric and restricted to a range that is considered as normal. Employment or price, for example, may rise or fall according to the set of possible outcomes (7) which determines a discrete stochastic process with the rate of change as random variable.

$$
\{-3 \%,-2 \%,-1 \%, 0 \%, 1 \%, 2 \%, 3 \%\} \quad p \text { equal } \mid \mathrm{t}
$$

Cursory inspection of this probability distribution, though, reveals that it does not constitute a fair game (c.f. Chung and AitSahlia, 2003, pp. 325-326). A player who starts with $1000 €$ and has a gain and then a loss of 3 percent ends up with 999 $€$. In order to obtain an unbiased random walk the set of possible outcomes has to be transformed according to a simple rule:

$$
\begin{gathered}
\left\{\frac{1}{1+3 \%}-1, \frac{1}{1+2 \%}-1, \frac{1}{1+1 \%}-1,0 \%, 1 \%, 2 \%, 3 \%\right\} \\
\{-2.91 \%,-1.96 \%,-0.99 \%, 0 \%, 1 \%, 2 \%, 3 \%\} \mid t \\
p \text { equal }
\end{gathered}
$$

With this probability distribution the expected gain or loss of a player at each consecutive step is equal and the condition of a fair game is satisfied. The expected absolute amounts, however, vary in the course of time depending on the cumulated

\footnotetext{
1 The term random economy has been introduced for the equilibrium analysis of pure exchange economies (Föllmer, 1974). It is adopted in the present paper without this specific connotation.
} 


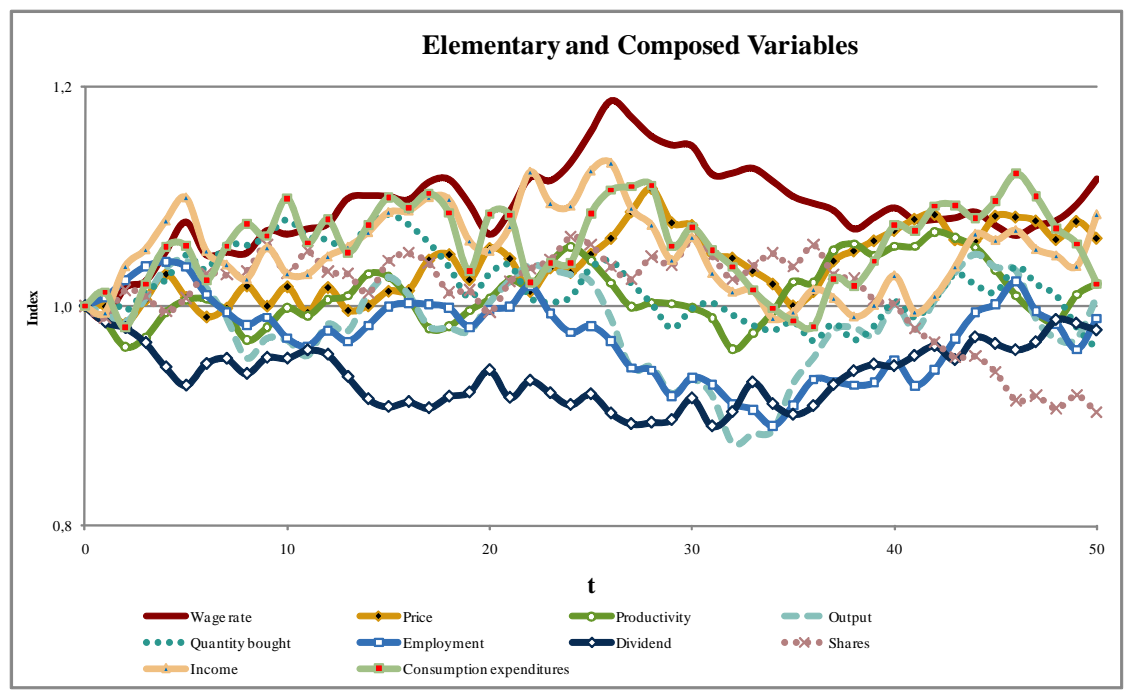

Figure 1: Development of the axiomatic variables of the random consumption economy over 50 periods

gains and losses. It is further assumed that the probability distributions of the variables are independent and remain identical over all periods.

When the probability distribution (8) is applied to the rates of change of all elementary variables, we arrive at the drifting consumption economy of which an example is given in Figure 1. The drifting economy evolves without any human intervention.

The assumptions enumerated above make it clear that the drifting economy is an idealization that brings Bachelier's seminal idea of the financial market process forward to the whole economy. With the generic evolutionary ingredients change and chance (Peirce, 1992, p. 219) the drifting economy is supposed to take over the role of the benchmark process.

\section{The path core}

Definitions are supplemented by connecting variables on the right-hand side of the identity sign that have already been introduced by the axioms (Boylan and O'Gorman, 2007, p. 431). With (9) wage income $Y_{W}$, distributed profit income $Y_{D}$, the expenditure ratio $\rho E$, the sales ratio $\rho X$, the distributed profit ratio $\rho D$, and the factor cost ratio $\rho F$ is defined:

$$
Y_{W} \equiv W L \quad Y_{D} \equiv D N \quad \rho_{E} \equiv \frac{C}{Y} \quad \rho_{X} \equiv \frac{X}{O} \quad \rho_{D} \equiv \frac{Y_{D}}{Y_{W}} \quad \rho_{F} \equiv \frac{W}{P R} \quad \mid t
$$

The axioms and definitions are consolidated to one single equation: 


$$
\frac{\rho_{F} \rho_{E}\left(1+\rho_{D}\right)}{\rho_{X}}=1 \quad \mid t
$$

The period core (10) determines the interdependencies of the measurable structural key ratios for each period. The factor cost ratio $\rho F$ summarizes the internal conditions of the firm. A value of $\rho F<1$ signifies that the real wage is lower than the productivity or, in other words, that unit wage costs are lower than the price, or in still other words, that the value of output exceeds the value of input. In this case the profit per unit is positive. Then we have the conditions in the product market. An expenditure ratio $\rho E=1$ indicates that consumption expenditures are equal to income and a value of $\rho x=1$ of the sales ratio means that the quantities produced and sold are equal in period $t$ or, in other words, that the product market is cleared. In the special case $\rho E=1$ and $\rho X=1$, that invokes the notion of an equilibrium with market clearing and budget balancing, the profit per unit is determined solely by the distributed profit ratio $\rho D$. The period core covers the key ratios about the firm, the market, and the income distribution and determines their mutual interdependencies.

The period value of each variable is now replaced by its development over time. From the period core (10) then follows:

$$
\frac{\rho_{F 0} \Pi \rho_{F t} \rho_{E 0} \Pi \rho_{E t}\left(1+\rho_{D 0} \Pi \rho_{D t}\right)}{\rho_{X 0} \Pi \rho_{X t}}=1
$$

The path core (11) describes the development of the whole system from the initial period up to period $t$ as a combination of the paths of the four key ratios. All path operators have the value 1 for $t=0$. Equation (11) thus boils down to:

$$
\frac{\Pi \rho_{F t} \Pi \rho_{E t}\left(1+\rho_{D 0} \Pi \rho_{D t}\right)}{\Pi \rho_{X t}\left(1+\rho_{D 0}\right)}=1
$$

When the initial value $\rho D O$ in (12) is conveniently determined nothing but the rates of change for each elementary variable remain as explananda. Structural axiomatization thus directly leads to a theory of change. The path core is the most economical expression of the axiom set. As a purely formal relationship it must always be satisfied independently of the actual formulation of any particular economic model. Different approaches can only differ in the explanation of the rates of change.

\section{Product market outcomes}

\subsection{Real and nominal flows}

The random movements of Figure 1 produce in the product market the outcome that is shown in Figure 2 as a pair of a $\rho X$-value on the abscissa and a $\rho E$-value on the ordinate which is represented by a dot for each period. Since $\rho X$ is a relation of real variables and $\rho E$ a relation of nominal variables the ratios themselves carry no 


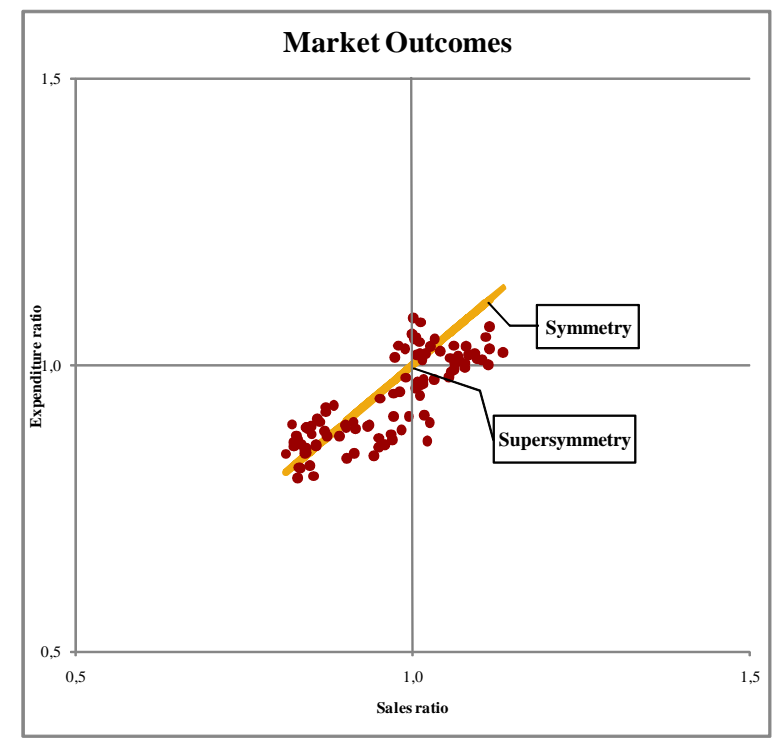

Figure 2: Product market outcomes of the drifting economy over 100 periods represented as dot for each period on the $\rho X-\rho E$-plane (same simulation as Figure 1)

dimension. Both are rational numbers. In structural axiomatic terms the former is a purely numerical expression of supply and the latter of demand.

Real and nominal flows determine the conditions in the product market. Therefore the outcome ratio - defined as the ratio of the ratios of real and nominal flows offers itself as a straightforward measure:

$$
\omega \equiv \frac{\rho_{E}}{\rho_{X}} \quad \mid t
$$

The outcome ratio in each period is determined by the configuration of the sales $\rho X$ and expenditure ratio $\rho E$. The configurations that produce exactly an outcome ratio of unity are situated on the diagonal in Figure 2 and are called symmetric. The overwhelming rest is scattered around the diagonal. One single point on the diagonal is supersymmetric, i.e. $\rho X=1, \rho E=1$. The outcome ratio is the most compact numerical characterization of the situation in the product market.

Why is the property of symmetry of special interest? Suppose the households decide in period $t$ not to spend their whole income as they did all the periods before, e.g. $\rho E=0.8$ instead of $\rho E=1.0$. At the given price the business sector cannot sell any longer the whole output and is left with an unsold stock of products at the end of period $t$, i.e. $\rho X=0.8$ instead of $\rho X=1.0$. This entails that the business sector cannot recoup a certain part of wage payments. The real counterpart of saving is now locked up in the storage depot. The outcome ratio is unity as in the previous period but no longer supersymmetric.

Suppose further that the households in period $t+1$ change their minds again and spend now not only their current income but in addition exactly that amount that had been saved in period $t$, i.e. $\rho E=1.2$. This amount is the exact nominal 
mirror image of the real stock of products in the storage depot at the given price. Symmetry entails that the business sector now sells the current output plus the whole stock of products, i.e. $\rho X=1.2$, at the given price. The outcome ratio is again unity. The sales revenues now exceed the current wage bill. In this stylized example the two non-market-clearing but symmetric period outcomes cancel out exactly and the outcome of the two periods taken together is supersymmetric. Symmetry is an intermediate form of order between pure randomness and supersymmetry. The drifting consumption economy tends to produce a symmetric outcome in the product market. The market is not cleared, but the real residuals correspond exactly to the nominal residuals.

\subsection{Prices}

The outcome ratio follows from the period core (10):

$$
\omega \equiv \frac{\rho_{E}}{\rho_{X}} \Leftarrow \frac{\rho_{E}}{\rho_{X}}=\frac{P}{\left(1+\rho_{D}\right) \frac{W}{R}} \mid t
$$

Let us keep all other variables constant for a moment, then we get the threedimensional relation between the coordinates of the $\rho X-\rho E$-plane and prices of Figure 3 which is given by:

$$
\frac{\rho_{E}}{\rho_{X}}=\frac{P}{(\cdot)} \quad \mid t
$$

To each point on the $\rho X-\rho E$-plane a price is assigned on the vertical axis. Vice versa, to each given price a rectangular hyperbola is assigned on the $\rho X-\rho E$-plane. In Figure 3 only the prices on the diagonals are shown. The prices on the diagonal $\rho X=\rho E$, i.e. for the symmetric outcomes, are equal to the supersymmetric price, i.e. for the special case $\rho X=\rho E=1$. The supersymmetric price and all other prices above the $\rho X-\rho E$-plane are located on the price surface that has the shape of the familiar demand schedule. The shape of the price surface is implicit in the axiom set and has nothing in common with the hypothesis that human beings maximize utility under a budget constraint. From (15) the familiar relation between price $P$ and quantity bought $X$ can be formally derived as a two-dimensional special case.

\subsection{Order out of randomness}

From Figure 2 it is intuitively clear that supersymmetry is the most improbable market outcome. How is it brought about? Simply crossing static supply-demand curves and invoking market 'forces' does not count as an answer. What we have to do is to let order emerge out of randomness. That is what evolution in Peirce's sense is all about:

... since law in general cannot be explained by any law in particular; the explanation must consist in showing how law is developed out of 


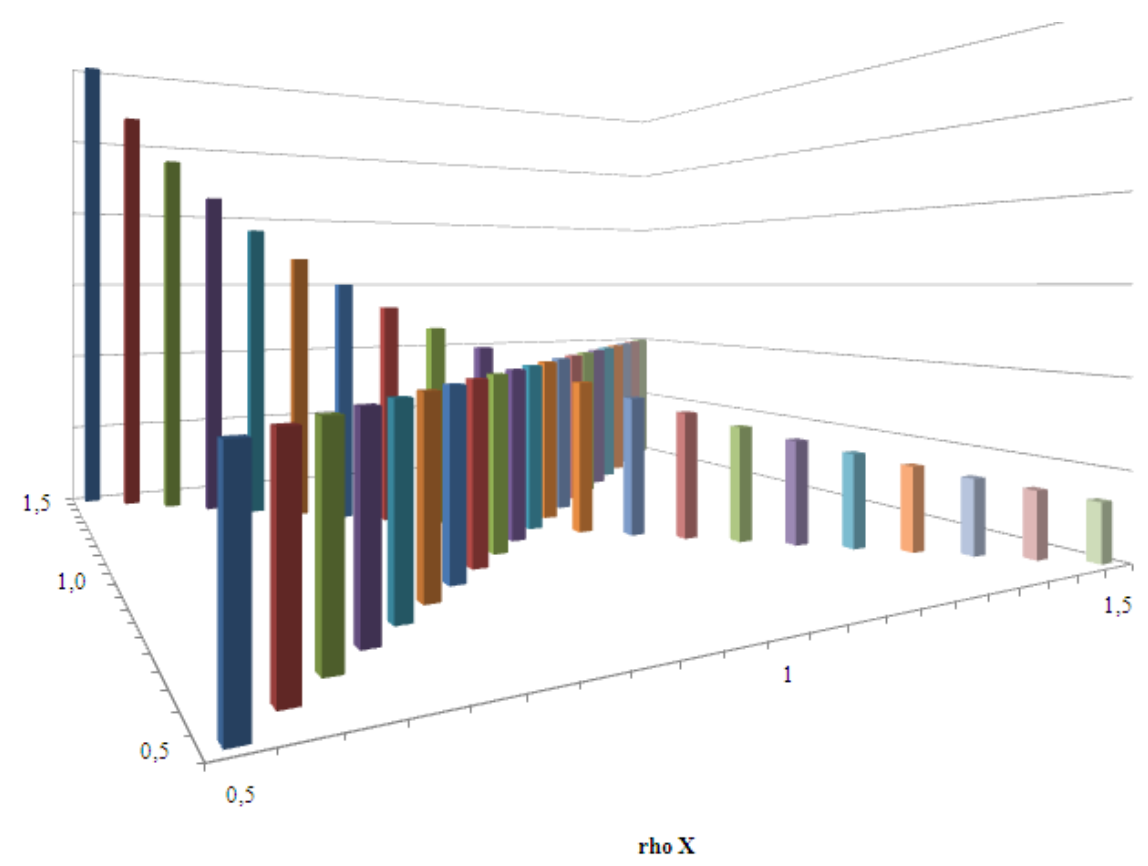

Figure 3: Price surface above the $\rho X-\rho E$-plane of Figure 2 (only the diagonals are shown)

pure chance, irregularity, and indeterminacy. (Peirce 1888, quoted in Kronz and McLaughlin, 2002, p. 192), see also (Prigogine, 2005, pp. 64-65)

Peirce's tenet that chance forms the basis of explanation and requires no explanation (Kronz and McLaughlin, 2002, p. 206) is taken up here as a methodological prescription that is in perfect harmony with the structural axiomatic approach.

The structural axiomatic model consists at the beginning of elementary stochastic processes. Therefore the outcomes in the product market are determined by the underlying probability distributions and the law of large numbers. It has to be demonstrated how, under fairly weak conditions, the axiomatic structure transforms random changes into a supersymmetric market outcome at the limit, that is, how the product market is almost surely cleared, and the household sector's budget is almost surely balanced without any human intervention.

\section{Symmetric market outcomes}

We now determine under which structural conditions the random consumption economy can achieve symmetry or even supersymmetry. From the path core (12) follows for the path of the outcome ratio that it depends on the paths of the factor cost ratio and the distributed profit ratio: 


$$
\Pi \omega \equiv \frac{1+\rho_{D 0}}{\Pi \rho_{F}\left(1+\rho_{D 0} \Pi \rho_{D}\right)} \quad \mid t
$$

Or explicitly:

$$
\Pi \omega \equiv \frac{1+\rho_{D 0}}{\frac{\Pi \dddot{W}}{\Pi \dddot{P} \Pi \dddot{R}}\left(1+\rho_{D 0} \frac{\Pi \dddot{D} \Pi \dddot{N}}{\Pi \dddot{W} \Pi \dddot{L}}\right)} \mid t
$$

It is assumed that the rates of change of the six elementary paths $W, P, R, D, N$, $L$ are determined by (8). The rate of change of the quantity bought $X$ plays no role. To determine the expected value of the path of the outcome ratio the general path operator (6) is resumed:

$$
\Pi \dddot{Z}_{t}=\left(1+\dddot{Z}_{1}\right)\left(1+\dddot{Z}_{2}\right) \ldots\left(1+\dddot{Z}_{t}\right)
$$

The expected value of the rate of change of the representative variable in period ${ }_{1}$ is given by:

$$
\begin{aligned}
\mathrm{E}\left[\dddot{Z}_{1}\right] & =\left(1+\dddot{Z}_{11}\right)\left(1+\dddot{Z}_{12}\right) \ldots\left(1+\dddot{Z}_{1 \mathrm{n}}\right)^{\frac{1}{n}}-1 \\
\text { with } \mathrm{n} & =\text { number of possible outcomes; } \mathrm{p} \text { equal }
\end{aligned}
$$

The expected value is zero for the distribution given by (8). The expected value of the path of the representative variable is for the general case given by:

$$
\mathrm{E}\left[\Pi \dddot{Z}_{t}\right]=\left(1+\mathrm{E}\left[\dddot{Z}_{1}\right]\right)\left(1+\mathrm{E}\left[\dddot{Z}_{2}\right]\right) \ldots\left(1+\mathrm{E}\left[\dddot{Z}_{t}\right]\right)=(1+\mathrm{E}[\dddot{Z}])^{t}
$$

According to our idealization the probability distributions are identical for all periods. When applied to (17) the specification for each of the six paths gives the result for the expected value of the path of the outcome ratio:

$$
\mathrm{E}\left[\Pi \omega_{t}\right]=\frac{1+\rho_{D 0}}{\underbrace{\frac{(1+\mathrm{E}[\dddot{W}])^{t}}{(1+\mathrm{E}[\dddot{P}])^{t}(1+\mathrm{E}[\dddot{R}])^{t}}}_{1}\left(1+\rho_{D 0} \frac{(1+\mathrm{E}[\dddot{D}])^{t}(1+\mathrm{E}[\dddot{N}])^{t}}{\underbrace{(1+\mathrm{E}[\dddot{W}])^{t}(1+\mathrm{E}[\dddot{L}])^{t}}_{1}}\right)}
$$

If the expected values of all rates of growth are zero then the expected value of the path of the outcome ratio is unity. Left on her owns the economy produces out of random variations almost certainly a symmetric outcome in the product market at $t \rightarrow \infty$.

In the general case we have to allow for probability distributions with an expected value greater (or smaller) than zero. The symmetrically drifting economy then turns into a growing economy. In order to attain a symmetric market outcome, the expected values cannot assume arbitrary values. From (21) follows that the 


\begin{tabular}{c|c|c|c|c|c|c|c|c|c|}
\multicolumn{2}{c|}{} & $\dddot{W}$ & $\dddot{P}$ & $\dddot{R}$ & $\dddot{D}$ & $\dddot{L}$ & $\dddot{N}$ & $\dddot{X}$ & $\mathrm{E}[\cdot]$ \\
\hline$(\mathrm{A})$ & $\mathrm{z}=0$ & $\mathrm{z}$ & $\mathrm{z}$ & $\mathrm{z}$ & $\mathrm{z}$ & $\mathrm{z}$ & $\mathrm{z}$ & - & 1 \\
\cline { 2 - 10 }$\Pi \omega$ & $\mathrm{z}>0, \mathrm{y}>0$ & $\mathrm{z}$ & 0 & $\mathrm{z}$ & $\mathrm{z}$ & $\mathrm{y}$ & $\mathrm{y}$ & - & 1 \\
\hline$(\mathrm{B})$ & $\mathrm{z}=0$ & $\mathrm{z}$ & $\mathrm{z}$ & - & $\mathrm{z}$ & $\mathrm{z}$ & $\mathrm{z}$ & $\mathrm{z}$ & 1 \\
\cline { 2 - 9 }$\Pi \rho_{E}$ & $\mathrm{z}>0, \mathrm{y}>0$ & $\mathrm{z}$ & 0 & - & $\mathrm{z}$ & $\mathrm{y}$ & $\mathrm{y}$ & $(1+\mathrm{z})(1+\mathrm{y})$ & 1 \\
\hline$(\mathrm{C})$ & $\mathrm{z}=0$ & - & - & $\mathrm{z}$ & - & $\mathrm{z}$ & - & $\mathrm{z}$ & 1 \\
\cline { 2 - 9 }$\Pi \rho_{X}$ & $\mathrm{z}>0, \mathrm{y}>0$ & - & 0 & $\mathrm{z}$ & - & $\mathrm{y}$ & - & $(1+\mathrm{z})(1+\mathrm{y})$ & 1 \\
\hline
\end{tabular}

Table 1: Expected value configurations that lead to symmetry or supersymmetry

expected rates of change of wage rate $W$, productivity $R$, and dividend $D$ have to be equal and the same applies to employment and the number of shares. The expected value of the price changes has to be zero (see row (A) in Table 1 for the configurations that lead to symmetry). Otherwise the expected value of the market outcome ratio cannot be unity. One important property of symmetry is that stochastic growth comes, by implication, along with stochastic price stability. The quantity bought $X$ is not relevant for symmetry, its rate of change is no constituent of equation (21).

Thus, as a first step result, one has that symmetry is maintained if all expected values of the rates of change of the elementary variable are either zero or, in the general case, equal within two groups of variables and zero for the price.

\section{Supersymmetric market outcomes}

To establish supersymmetry the expected values of the paths of the expenditure and the sales ratio that are given by (22) and (23) both have to be unity. To realize this, conditions (24) and (25) have to be substituted:

$$
\begin{gathered}
\mathrm{E}\left[\Pi \rho_{E}\right]=\frac{(1+\mathrm{E}[\dddot{P}])^{t}(1+\mathrm{E}[\dddot{X}])^{t}}{(1+\mathrm{E}[\dddot{W}])^{t}(1+\mathrm{E}[\dddot{L}])^{t}+(1+\mathrm{E}[\dddot{D}])^{t}(1+\mathrm{E}[\dddot{N}])^{t}}=1 \\
\mathrm{E}\left[\Pi \rho_{X}\right]=\frac{(1+\mathrm{E}[\dddot{X}])^{t}}{(1+\mathrm{E}[\dddot{R}])^{t}(1+\mathrm{E}[\dddot{L}])^{t}}=1 \\
(1+\mathrm{E}[\dddot{X}])^{t}=(1+\mathrm{E}[\dddot{R}])^{t}(1+\mathrm{E}[\dddot{L}])^{t} \\
(1+\mathrm{E}[\dddot{P}])^{t}=2 \Rightarrow \mathrm{E}[\dddot{P}]=2^{\frac{1}{t}}-1 \rightarrow 0
\end{gathered}
$$

Row (B) and (C) in Table 1 summarize the expected value configurations for the growing economy that lead to stochastic supersymmetry in the product market. Figures 4 and 5 visualize the result of a simulation over 1.000 periods for the probability distribution $\dddot{R}=\{-0.99 \%, 0 \%, 1 \%, 2 \%, 3 \%\}=\mathrm{z}$ and $\dddot{L}=\{0 \%, 1 \%, 2 \%\}=\mathrm{y}$ that both have an expected value $>0$, i.e. $1.02 \%$ and $1.01 \%$ respectively. 


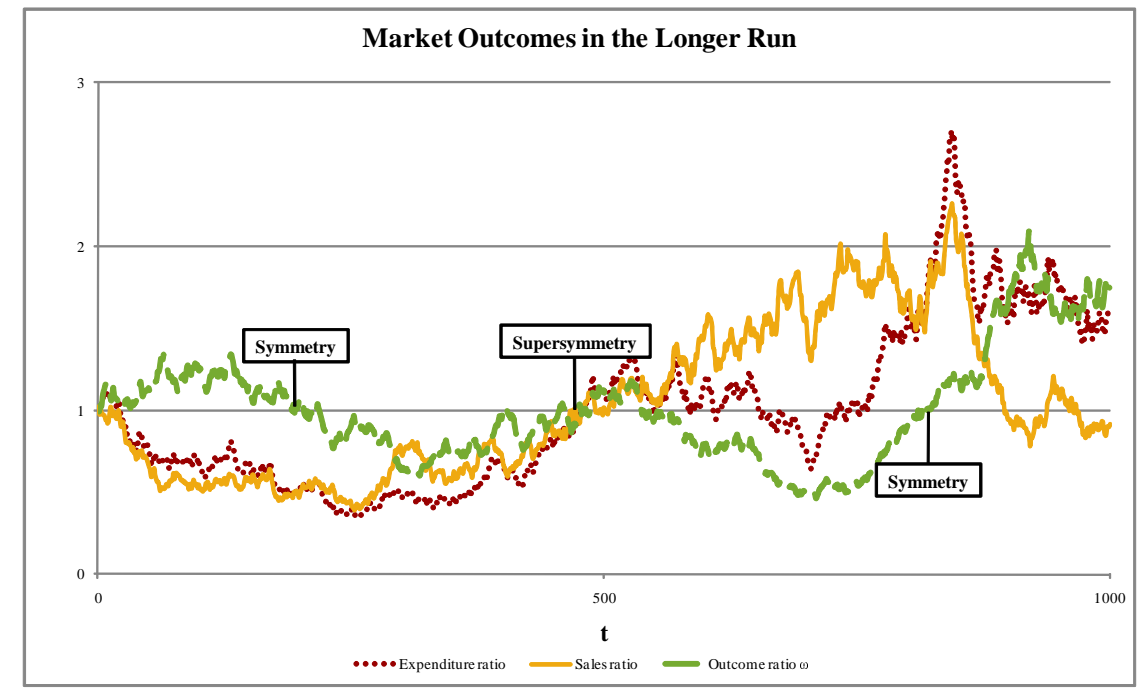

Figure 4: Development of the expenditure-, sales-, and outcome ratio over 1.000 periods

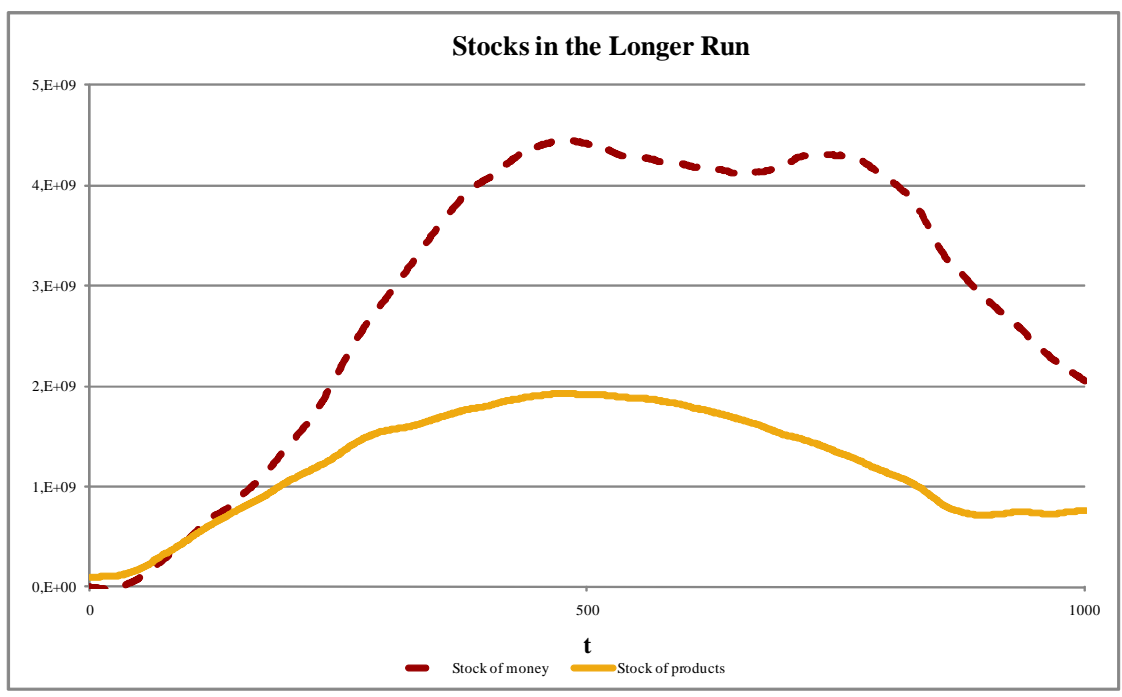

Figure 5: Development of the stocks of products and money over 1.000 periods 
The path of the outcome ratio in Figure 4 thus exemplifies the general case of a growing random economy. In the selected run the path remains over 1.000 periods in the neighborhood of unity (that, of course, does not come to pass at every run ${ }^{2}$ ) and realizes the supersymmetry condition $\rho X=1$ and $\rho E=1$ around period ${ }_{500}$. In this period the market is cleared and the household sector's budget is balanced.

In relation to the stock of products in Figure 5 the sales ratio in Figure 4 takes the role of the first derivative. The same holds for the stock of money and and the expenditure ratio (both stocks are derived in the Appendix). If the respective ratio is unity (not zero as in continuous calculus) the corresponding stock remains unchanged. Supersymmetry therefore means that the real and nominal stocks in the same period reach a minimum, maximum or turning point. This happens around period $_{500}$. Note that this discrete calculus is an implicit property of the structural axiom set.

Due to the statistical laws both stocks almost certainly converge to zero 'in the long run'. The formal conditions of the limit state are given by:

$$
\sum_{t=1}^{t} \Delta M_{H t}=0 \quad \text { and } \quad \sum_{t=1}^{t} \Delta O_{t}=0
$$

We, therefore, have to discriminate between supersymmetry for one period, which is defined as $\rho X=1$ and $\rho E=1$, and supersymmetry over the whole time span, which is defined by (26).

Profit has been defined in (Kakarot-Handtke, 2011a, p. 6-12) and determined for the supersymmetric end state. It holds that cumulated profits are equal to cumulated distributed profits:

$$
\sum_{t=1}^{t} \Delta Q_{f i t}=\sum_{t=1}^{t} Y_{D t}
$$

It is important to note that reality is, of course, not perfectly symmetric and does for example not allow for negative values of the stock of products which occur when the sales ratio is, more often than not, below unity. These obvious restrictions are neglected here. In the unconstrained simulation of the pure random consumption economy the negative sections of the inventory path are regarded as virtual.

As a precisely defined mathematical object the supersymmetric consumption economy has specific statistical properties which, however, are not known at the moment and not required in order to explore the economic implications that are our main concern. One phenomenon, indeed, should be mentioned. It has been observed by Slutzky(1937, p. 114) that the summation of random causes may produce cyclic processes in the economy (and elsewhere). This seems also to be the case for the outcome ratio in Figure 4 although the cyclic pattern does not result from a simple summation but from the intricate economic structure that is given with the axioms.

\footnotetext{
2 The simulation is somewhat biased because of the rounding of the negative rates of change. This effect is multiplicative and cumulative and the expenditure- and the sales ratio are more often above unity than below.
} 
This implies - tentatively - that randomness contributes a significant part to the explanation of cycles (Barnett, 2006).

\section{Properties of structural laissez-faire}

The outcome ratio describes a supersymmetric path if the probability distributions for the elementary axiomatic variables have the following properties.

(i) The expected values of the rates of change of wage rate $\dddot{W}$, productivity $\dddot{R}$ and dividend $\dddot{D}$ are uniform within the group. When the random consumption economy is left to itself then, roughly speaking, the wage rate rises (or falls) 'in the long run' with productivity and the dividend marches in lockstep with the wage rate.

(ii) The expected values of the rates of change of employment $\dddot{L}$ and the number of shares $\dddot{N}$ are uniform within the group. Both variables move in lockstep 'in the long run'.

(iii) The expected value of the rates of change of the price converges to zero as $t \rightarrow \infty$. Roughly speaking we have price stability 'in the long run'. Or, to employ a metaphor, the price is, like the sun, is the stationary center of the economic system and two distinct groups of axiomatic variables revolve around it.

(iv) The expected value of the rates of change of the quantity bought $\dddot{X}$ is the product of the expected values of productivity $\dddot{R}$ and employment $\dddot{L}$, i.e. $X$ has to absorb the growth of $R$ and $L$. Equation (24) amounts to the specification of Say's law for the product market in structural axiomatic terms. Note that (24) is a condition and not (pace Say) an economic "law".

(v) If all expected values are zero then one gets the special case of the drifting economy with supersymmetry at the limit. It is condition (iv) which makes the difference between symmetry and supersymmetry.

In the general axiomatic growth model market outcomes are determined by the underlying probability distributions. Stochastic supersymmetry means that the real and nominal flows in the product market almost surely converge and the cumulated real and nominal stocks approach zero at $t \rightarrow \infty$. This implies that the limit price is equal to the price in the initial period.

Points (i) to (iv), that parallel equations (22) to (25), are referred to as stochastic supersymmetry conditions. It is noteworthy that the classical bone of contention, Say's law (Morishima and Catephores, 1988, pp. 24-26), (Vickers, 1995, p. 7-14), (Davidson, 2002, pp. 19-21), makes an unexpected reappearance as a condition for supersymmetry in the product market of the pure random consumption economy. 
Supersymmetry in the product market is compatible with any level of employment. In order to assure stochastic full employment an additional condition is needed, namely, that the expected value of the random labor supply changes is equal to the expected value of labor input changes. This condition does not follow from the structural axiom set.

If all these conditions are met we get the best of all possible random consumption economies with product market clearing, budget balancing, price stability, and full employment. In this theoretical limiting case the supersymmetric process is the concrete manifestation of the invisible hand's modus operandi. Her operations are ruled by statistical laws and the supersymmetry conditions and therefore comply to the methodological minimum principle. Typifying laissez-faire in the literal sense stochastic supersymmetry has one serious drawback: it is only to be found beyond the human time horizon.

\section{Shortening the long run}

Equilibrium is the end state of a process. Process is therefore logically prior to equilibrium. Not every process leads to an equilibrium. Process is therefore the general concept and equilibrium is a special case. A simultaneous equilibrium is a contradiction in terms. What we have in fact is the solution of a set of equations with a metaphor attached to it.

$\ldots$, we must be prepared to acknowledge translational rigor as one aspect of logical rigor. Unfortunately, the experience of mathematical economics to date has been to subordinate translational rigor to mathematical rigor, a double standard with no logical justification. The result is naive translation, the loose paraphrasing or informal interpretation of mathematical formulae in such a way as to portray them as expressing ideas and propositions that closer inspection shows they do not express. (Dennis, 1982, p. 700), original emphasis

The timeless equilibrium of general equilibrium theory is a loose paraphrasing of a fixed point. The last grain of logic is finally lost when the non-existing equilibrium (the smile of the Cheshire cat) is projected into the future, the undefined long run. The invocation of market 'forces' that make things turn out in the end to everybody's satisfaction borders to animism. It would be closer to facts to characterize the limit of the random consumption economy at $t \rightarrow \infty$ as equilibrium, but nothing would be gained by the further usage of this discredited notion (cf. Kirzner, 1998, p. 39, Mirowski, 1981, p. 606).

A random walk is an abstract process without a discernible or dominant 'force'. As Georgescu-Roegen has pointed out:

The only solution ... is to admit that there is a factor at work in nature which ... combines regularity and irregularity in the manner expressed 
by the Law of Large Numbers. Consequently, when we invoke that law for natural phenomena, we invoke a law of nature not a mathematical tautology. Random is a cause, and the Law of Large Numbers is its effect. (Georgescu-Roegen, 1971, p. 172), original emphasis

The well-defined properties of a one-dimensional random walk make it possible to calculate the expected number of steps until it hits a target value. This gives the woolly notion of 'the long run' a real meaning. What we would like to know is how long it takes until the nominal and real stocks in the random consumption economy approach zero. This economy, though, is composed of seven independent random walks and it is unknown at the moment whether the question has a calculable answer. Figure 5 at least gives a rough idea of the time that it takes for the system to return to zero nominal and real stocks. This rapprochement to cumulated supersymmetry, though, is transitory and not to be confused with the limit at $t \rightarrow \infty$.

Human beings cannot wait until the law of large numbers brings about cumulative supersymmetry for the first time. What could they do to speed up the process? The analysis of the supersymmetric random consumption economy suggests some simple behavioral rules:

- Adapt the wage rate to the development of productivity.

- Let the dividend move with the wage rate.

- Hire all labor supply at the actual wage rate.

- Let the number of shares move with employment.

- Don't change the price.

- Obey Say's "law" and buy whatever is produced in one period at the actual price.

These rules follow from the structural properties of the pure consumption economy and they guarantee supersymmetry in the product market and full employment in each period. In addition they guarantee a stable distribution of output (KakarotHandtke, 2011b, pp. 8-12) and cumulated profits greater than zero according to (27). Needless to emphasize that human beings follow other rules, which are mainly based on parochial realism. This, though, cannot lead to better overall outcomes.

\section{Conclusions}

Behavioral assumptions, rational or otherwise, are not solid enough to be eligible as first principles of theoretical economics. Hence all endeavors to lay the formal foundation on a new site and at a deeper level actually need no further vindication. The present paper suggests three non-behavioral axioms and a temporal link as groundwork for the formal reconstruction of the evolving money economy. 
The axioms together with random rates of change for all elementary axiomatic variables constitute a pure random consumption economy. No behavioral hypotheses are employed. The conditions for market clearing and budget balancing at the limit $t \rightarrow \infty$ are:

- The expected values of the rates of change of wage rate, productivity and dividend are uniform within the group.

- The expected values of the rates of change of employment and the number of shares are uniform within the group.

- The expected value of the rates of change of the price converges to zero.

- The expected value of the rates of change of the quantity bought $X$ is the product of the expected values of productivity and employment. This condition amounts to the specification of Say's law for the product market in structural axiomatic terms.

Supersymmetry in the product market is compatible with any level of employment. In order to assure stochastic full employment an additional condition is needed, namely, that the expected value of the random labor supply changes is equal to the expected value of labor input changes.

The formal properties of the axiomatic random economy translate into simple behavioral rules that guarantee market clearing, budget balancing, full employment, positive profits, and a stable distribution of output in all consecutive periods. A deviance of actual human behavior from the structural logic leads to frustrated plans and expectations.

\section{References}

Barnett, V. (2006). Changing an Interpretation: Slutzky's Random Cycles Revisted. European Journal of the History of Economic Thought, 13(3): 411-432. DOI 10.1080/09672560600875596. URL http://www.tandf.co.uk/journals.

Boylan, T. A., and O'Gorman, P. F. (2007). Axiomatization and Formalism in Economics. Journal of Economic Surveys, 21(2): 426-446.

Cairnes, J. E. (1875). The Character and Logical Method of Political Economy. New York, NY: Harper.

Chung, K. L., and AitSahlia, F. (2003). Elementary Probability Theory. New York, NY, Berlin, Heidelberg: Springer.

Davidson, P. (2002). Financial Markets, Money and the Real World. Cheltenham, Northampton, MA: Edward Elgar. 
Davis, M., and Etheridge, E. (2006). Louis Bachelier's Theory of Speculation. Princeton, NJ, Oxford: Princeton University Press.

Dennis, K. (1982). Economic Theory and the Problem of Translation (I). Journal of Economic Issues, 16(3): 691-712. URL http://www.jstor.org/stable/4225211.

Föllmer, H. (1974). Random Economies with Many Interacting Agents. Journal of Mathematical Economics, 1: 51-62.

Foster, J. (2005). The Self-Organizational Perspective on Economic Evolution: A Unifying Paradigm. In K. Dopfer (Ed.), The Evolutionary Foundations of Economics, pages 367-390. Cambridge: Cambridge University Press.

Georgescu-Roegen, N. (1971). The Entropy Law and the Economic Process. Cambridge, MA: Cambridge University Press.

Hilbert, D. (2005). Axiomatic Thought. In W. Ewald (Ed.), From Kant to Hilbert, volume II, pages 1107-1115. Oxford, New York, NY: Oxford University Press. (1918).

Ingrao, B., and Israel, G. (1990). The Invisible Hand. Cambridge, MA, London: MIT Press.

Kakarot-Handtke, E. (2011a). Beginning, Crises, and End of the Money Economy. SSRN Working Paper Series, pages 1-29. URL http://ssrn.com/abstract=1855578.

Kakarot-Handtke, E. (2011b). The Coherency of Money, Profit, Price, and Distribution. SSRN Working Paper Series, pages 1-15. URL http://ssrn.com/abstract= 1858031.

Kakarot-Handtke, E. (2011c). The Pure Logic of Value, Profit, Interest. SSRN Working Paper Series, pages 1-21. URL http://ssrn.com/abstract=1838203.

Keen, S. (2004). Improbable, Incorrect or Impossible: The Persuasive but Flawed Mathematics of Microeconomics. In E. Fullbrook (Ed.), A Guide to What's Wrong With Economics, pages 209-222. London: Anthem Press.

Kirzner, I. M. (1998). The Driving Force of the Market. In D. L. Prychitko (Ed.), Why Economists Disagree, pages 37-52. Albany, NY: State University of New York Press.

Kreuzenkamp, H. A., and McAleer, M. (1995). Simplicity, Scientific Inference and Econometric Modeling. Economic Journal, 105: 1-21. URL http://www.jstor. org/stable/2235317.

Kronz, F. M., and McLaughlin, A. L. (2002). The Complementary Roles of Chance and Lawlike Elements in Peirce's Evolutionary Cosmology. In H. Atmanspacher, and R. Bishop (Eds.), Between Chance and Choice, pages 189-207. Exeter: Imprint Academic. 
LeRoy, S. F. (1989). Efficient Capital Markets and Martingales. Journal of Economic Literature, 27(December): 1583-1621.

Mill, J. S. (2004). On the Definition of Political Economy; and the Method of Investigation Proper to it., volume PA 18202, pages 93-125. Electronic Classic Series: Pennsylvania State University. (1844).

Mill, J. S. (2006). A System of Logic Ratiocinative and Inductive. Being a Connected View of the Principles of Evidence and the Methods of Scientific Investigation, volume 8 of Collected Works of John Stuart Mill. Indianapolis, IN: Liberty Fund. (1843).

Mirowski, P. (1981). Is There a Mathematical Neoinstitutional Economics? Journal of Economic Issues, 15(3): 593-613. ISSN 00213624. URL http://www.jstor.org/ stable/4225064.

Mirowski, P. (1995). More Heat than Light. Cambridge: Cambridge University Press.

Mirowski, P. (2004). The Effortless Economy of Science? Durnham, London: Duke University Press.

Morishima, M., and Catephores, G. (1988). Anti-Say's Law versus Say's Law: A Change in Paradigm. In H. Hanusch (Ed.), Evolutionary Economics, pages 23-52. Cambridge: Cambridge University Press.

Nelson, R. R. (1995). Recent Evolutionary Theorizing About Economic Change. Journal of Economic Literature, 33(March): 48-90.

Niehans, J. (1994). A History of Economic Theory. Baltimore, MD, London: Johns Hopkins University Press.

Peirce, C. S. (1992). A Guess at the Riddle. In N. Houser, and C. Kloesel (Eds.), The Essential Peirce. Selected Philosophical Writings., volume 1, pages 245-279. Bloomington, IN: Indiana University Press.

Poincaré, H. (2007). Science and Method. New York, NY: Cosimo. (1914).

Prigogine, I. (2005). The Rediscovery of Value and the Opening of Economics. In K. Dopfer (Ed.), The Evolutionary Foundations of Economics, pages 61-69. Cambridge: Cambridge University Press.

Prychitko, D. L. (Ed.) (1998). Why Economists Disagree. Albany, NY: State University of New York Press.

Rosenberg, A. (1994). What is the Cognitive Status of Economic Theory? In R. E. Backhouse (Ed.), New Directions in Economic Methodology, pages 216-235. London: Routledge. 
Schumpeter, J. A. (1954). Economic Doctrine and Method. London: Allen and Unwin.

Slutzky, E. (1937). The Summation of Random Causes as the Source of Cyclic Processes. Econometrica, 5(2): 105-146. URL http://www.jstor.org/stable/ 1907241.

Stigum, B. P. (1991). Toward a Formal Science of Economics: The Axiomatic Method in Economics and Econometrics. Cambridge, MA: MIT Press.

Suppes, P. (1968). The Desirability of Formalization in Science. The Journal of Philosophy, 65(20): 651-664.

Vickers, D. (1995). The Tyranny of the Market. A Critique of Theoretical Foundations. Ann Arbor; MI: University of Michigan Press.

\section{Appendix}

If income is higher than consumption expenditures the household sector's stock of money increases. The change in period $t$ is defined as:

$$
\Delta M_{H} \equiv Y-C \equiv\left(1-\rho_{E}\right) Y \quad \mid t
$$

The stock of money at the end of an arbitrary number of periods is defined as the numerical integral of the previous changes of the stock plus the initial endowment:

$$
M_{H} \equiv \sum_{t=1}^{t} \Delta M_{H t}+M_{H 0}
$$

The change of the stock of products in period $t$ is defined as the excess between output and the quantity bought by the households:

$$
\Delta O \equiv O-X \equiv\left(1-\rho_{X}\right) O \quad \mid t
$$

The stock at the end of an arbitrary number of periods is given as the numerical integral of all previous stock changes plus the initial endowment:

$$
B_{t} \equiv \sum_{t=1}^{t} \Delta O_{t}+B_{0}
$$

Correspondence address:

AXEC

Egmont Kakarot-Handtke 
Hohenzollernstraße 11

80801 Munich, Germany

e-mail: handtke@axec.de

Papers on SSRN: http://ssrn.com/author=1210665

(C) 2011 Egmont Kakarot-Handtke 